\title{
How Important is Human Capital? A Quantitative Theory Assessment of World Income Inequality *
}

\author{
Andrés Erosa \\ University of Toronto
}

\author{
Tatyana Koreshkova \\ Concordia University
}

February 2007

\author{
Diego Restuccia \\ University of Toronto
}

\begin{abstract}
We develop a quantitative theory of human capital investment in order to evaluate the magnitude of cross-country differences in total factor productivity (TFP) that explains the variation in per-capita incomes across countries. We build a heterogeneousagent economy with cross-sectional variation in ability, schooling, and expenditures on schooling quality. In our theory, the parameters governing human capital production and random ability process have important implications for a set of cross-sectional statistics - Mincer return, variance of earnings, variance of schooling, and intergenerational correlation of earnings. These restrictions of the theory and U.S. household data are used to pin down the key parameters driving the quantitative implications of the theory. Our main finding is that human capital accumulation strongly amplifies TFP differences across countries. In particular, we find an elasticity of output per worker with respect to TFP of 2.8: a 3-fold difference in TFP explains a 20-fold difference in output per worker. We argue that the cross-country differences in human capital implied by the theory are consistent with a wide array of evidence including earnings of immigrants in the United States, average mincer returns across countries, and the relationship between average years of schooling and per-capita income across countries. The theory implies that using Mincer returns to measure human capital understates differences across countries by a factor of 2 .
\end{abstract}

Keywords: output per worker, TFP, human capital, heterogeneity, inequality. JEL Classification: O1.

${ }^{*}$ The authors would like to thank seminar and workshop participants at Queens University, Arizona State University, ASU Development Workshop, HEC Montreal, University of Montreal, Federal Reserve Bank of Richmond, 2006 NBER Summer Institute Growth Workshop, McGill University, University of TexasAustin, University of Southern California, Bank of Canada Productivity Workshop, Concordia University, Carleton University, University of Tokyo and Seoul National University. The paper has previously circulated under the title "On the Aggregate and Distributional Implications of Productivity Differences Across Countries." Contact Information: Department of Economics, University of Toronto, 150 St. George Street, Toronto, Ontario M5S3G7, Canada. E-mail: andres.erosa@utoronto.ca; tkoreshk@alcor.concordia.ca; and diego.restuccia@utoronto.ca. 


\section{Introduction}

One of the most important challenges faced by economists is to explain the observed large differences in per capita income across countries. In this paper we develop a quantitative theory of human capital investments in order to evaluate the magnitude of cross-country differences in the total factor productivity (TFP) that explains the variation in per capita income across countries. Building a quantitative theory allows us to circumvent two major problems faced by growth accounting exercises. First, to date, there are no reliable crosscountry measures of the quality of schooling across countries. If this quality is positively associated with the level of economic development, the residual in growth accounting exercises overstates the cross-country differences in TFP. A second problem arises due to the (unobserved) covariance of TFP with measures of physical and human capital, which renders output variance decomposition difficult.

Our approach consists of developing a theory of human capital investments - schooling time and expenditures on schooling quality - that can be used to quantitatively assess the sources of cross-country income differences. We show that the quantitative implications of human capital theory hinge crucially on the value of the elasticity of human capital with respect to the expenditure on goods. ${ }^{1}$ The intuition is simple: If schooling requires only time inputs, a change in the wage rate affects equally the benefits and the costs of human capital accumulation, leaving the optimal level of human capital unchanged. On the contrary, when schooling requires only inputs of goods, an increase in the wage rate raises benefits but not the costs of schooling, hence increasing the optimal human capital stock. Therefore, the relative importance of time versus goods inputs determines the responsiveness of human capital to differences in the wage rate or TFP. ${ }^{2}$

\footnotetext{
${ }^{1}$ Trostel (1993) and Erosa and Koreshkova (forthcoming) make a similar point when studying the taxation of income.

${ }^{2}$ Bils and Klenow (2000) point out that the production of human capital is more intensive in time inputs than the production of output goods. They and Klenow and Rodriguez-Clare (1997) argue that, by using a one-sector growth model, Mankiw, Romer, and Weil (1992) overstate the importance of goods inputs in the production of human capital and, thus, obtain results that understate TFP differences across countries.
} 
Developing a quantitative theory, in turn, is a challenging task due to the lack of conclusive micro evidence on the expenditure elasticity of human capital: some key human capital determinants, such as individual ability and private expenditures on education (including those outside of formal schooling), are not observed. We address this problem by building a theory of heterogeneous agents with cross-sectional variation in ability, schooling, and expenditures on schooling quality. In our theory, the parameters governing the human capital technology and random ability process have important implications for a set of cross-sectional statistics - Mincer return, variance of earnings, variance of schooling, and intergenerational correlation of earnings - estimates of which are actually available in the data. Thus we use the restrictions of the theory and U.S. household data to pin down the key parameters driving the quantitative implications of the theory. We then use the theory to study income inequality across countries and, in particular, to quantitatively assess how variations in TFP are amplified through human capital accumulation into larger differences in output per worker across countries.

Our main finding is that human capital accumulation strongly amplifies TFP differences across countries: under the benchmark calibration, the elasticity of output per worker with respect to TFP is 2.8. This implies that a 3 -fold difference in TFP explains a 20-fold difference in the output per worker, observed between the 10 percent richest and 10 percent poorest countries in the world. In contrast, without human capital accumulation, the same difference in TFP generates only a 5-fold difference in output per worker, with physical capital being the sole source of amplification. Moreover, the theory implies that using Mincer returns to measure human capital stocks - as typically done in growth accounting exercises - understates differences in human capital across rich and poor countries by a factor of 2 . This occurs because Mincer returns do not capture differences in schooling quality across countries, which our theory finds to be quantitatively important.

To evaluate the robustness of our quantitative theory, we perform a sensitivity analysis. While the calibration of our model involves solving a multi-dimensional mapping from pa- 
rameters to targets, the target for the share of time inputs in expenditures on human capital has a first-order effect on the goods elasticity of human capital (and hence, on the TFP elasticity of output per worker). In our baseline calibration, we use an estimate from Kendrick (1976) and the U.S. Department of Education (1996) to set the target for the time share at 90 percent. ${ }^{3}$ Since this target plays such a crucial role in our results and its accurate estimate is difficult to obtain, we recalibrate the model economy by targeting alternative values for the time share: 100, 95, 90, and 85 percent. We find that the TFP elasticity of output per worker varies substantially across the calibrated economies: from 1.49 for the time share of 100 percent to 3.6 for the time share of 85 percent. These figures conceal a dramatic variation in the amplification effect of TFP: a 3-fold difference in TFP translates into a variation in output per worker that ranges from 5-fold (time share 100 percent) to a 54-fold difference (time share 85 percent). Given the high sensitivity of results, we confront the predictions of the calibrated models with cross-country data. To this end, for each of the specifications, we generate artificial cross-country data by simulating economies that vary in their relative levels of TFP.

Our baseline model economy successfully replicates the cross-country variation in schooling and Mincer returns (and so does the economy with a time share of 85 percent). On the contrary, the model with only time inputs generates neither schooling nor Mincer return variation across countries - an implication that is grossly at odds with the data. Moreover, the absence of goods in our human capital theory means no cross-country differences in schooling quality and hence in human capital, which contradicts the empirical findings of Borjas (1987) and Hendricks (2002) on immigrant earnings in the United States. In particular, Borjas estimates the elasticity of schooling quality with respect to the home-country per capita income to be 0.12 . In our model economies, this elasticity ranges from 0.07 (time share 95 percent) to 0.16 (time share 85 percent), with our baseline calibration delivering

\footnotetext{
${ }^{3}$ While this observation motivates Bils and Klenow (2000) to abstract from modeling investment of goods altogether in human capital accumulation, our findings indicate that even a small 10 percent share of goods in human-capital expenditures generates a large amplification effect of TFP differences across countries.
} 
0.10, the closest value to the Borjas' estimate. Furthermore, among the alternatives, the baseline calibration provides the most consistent account of Hendricks' evidence on immigrant earnings. Therefore, we conclude that the cross-country data supports a time-share target close to 90 percent, as is the case in our baseline calibration, and an associated TFP elasticity of output per worker of 2.8 .

The paper proceeds as follows. The next section describes in detail the economic environment. In section 3, we consider a version of the model economy with complete markets to show how the quantitative implications of the theory for income inequality -within and across countries- depend crucially on the expenditure elasticity of human capital. We also derive some valuable insights that help us motivate our calibration strategy. Section 4 lays out the calibration of the benchmark economy and discusses some properties of this economy. In section 5, we evaluate the aggregate impact of TFP differences across countries, perform a sensitivity analysis, and compare our findings to related papers in the literature. Section 6 concludes.

\section{Economic environment}

We consider an economy populated by overlapping generations of people who are altruistic toward their descendants. People are heterogeneous in skills and physical assets and face idiosyncratic (uninsurable) uncertainty about their labor earnings. Investment in human capital involves the investment of children's time and expenditures by parents that affect the quality of the human capital of their children. Parents cannot borrow to finance investment in human capital. Since the analysis in this paper focuses on steady states, time subscripts are omitted in the description of the model and use a prime to indicate the next period value of a given variable.

Demographic structure There is a large number of dynasties (mass one). The economy is populated by overlapping generations of people who live for 5 periods and are altruistic 
toward their descendants. The model period is set to 16 years. People live three periods as adults and two periods as children. Panel A of Table 1 summarizes the demographic structure in the model and the mapping between age in the model and real age in the data. In order to match individual life expectancy in the model to that observed in the United States, we introduce an exogenous probability of survival from period 4 to period $5, \phi$. A household is composed of a parent-child pair in the first two stages and a retired adult in the last stage. These three stages of the life cycle of households are described in Panel B of Table 1.

Table 1: Demographic Structure and Life-cycle Stages of Households

Panel A: Demographic Structure

\begin{tabular}{ccl}
\hline Model Age & Real Age & Name \\
1 & $6-21$ & child \\
2 & $22-37$ & old child \\
3 & $38-53$ & young adult \\
4 & $54-69$ & old adult \\
5 & $70-85$ & retired adult \\
\hline
\end{tabular}

Panel B: Life-cycle Stages of Households

\begin{tabular}{cllll}
\hline Stage & Adult & Adult's Age & Child & Child's Age \\
1 & young & $38-53$ & child & $6-21$ \\
2 & old & $54-69$ & old child & $22-37$ \\
3 & retired & $70-85$ & - & - \\
\hline
\end{tabular}

Production technologies Output is produced with a constant returns to scale technology,

$$
Y=A K^{\alpha} H^{1-\alpha}, \quad 0<\alpha<1
$$

where $Y$ denotes output, $K$ represents physical capital services, $H$ stands for aggregate human capital services, and $A$ is total factor productivity (TFP). Output can be consumed 
$C$, invested in physical capital $X$, and invested in human capital $E$. Feasibility requires $C+X+E=Y$. Physical capital is accumulated according to

$$
K^{\prime}=(1-\delta) K+A_{k} X, \quad A_{k} \leq 1,
$$

where $A_{k}$ is a parameter determining the productivity of investment in physical capital (i.e., the effectiveness with which current period output can be transformed into capital available for production in the following period). The aggregate human capital $H$ is given by the sum of human capital services in the production of goods. Human capital of an individual is produced with the inputs of time $(s)$ and expenditures in human capital quality $(e)$ according to the following production function:

$$
h^{\prime}=z^{\prime}\left(s^{\eta} e^{1-\eta}\right)^{\xi} \quad \eta, \xi \in(0,1),
$$

where $z^{\prime}$ is a stochastic earnings (or learning) ability. Individuals are ex-ante identical in their endowment of time but ex-post heterogeneous in their earnings ability. A unit of schooling time (quantity of schooling) is produced with one unit of child's time $(s)$, and $\bar{l}$ units of market human capital services. In other words, schooling requires own time and time purchased in the market. Earnings ability is transmitted across generations according to a discrete Markov transition matrix $Q\left(z, z^{\prime}\right)$, where $q_{i, j}=\operatorname{Pr}\left(z^{\prime}=z_{i} \mid z=z_{j}\right)$. We abstract from on-the-job human capital accumulation. In order to capture a realistic life-cycle profile of wages, we instead assume an exogenous path of life-cycle productivity $\left(\psi_{c}, \psi_{y}, \psi_{o}\right)$ for children, young adults, and old adults. The productivity of old children is normalized to one. Our abstraction is motivated by tractability reasons as well as some empirical evidence across countries. Using the coefficients for returns to experience for each country reported in Bils and Klenow (2000), we found that the earnings of a worker with 20 years of experience relative to a worker with 10 years of experience is not systematically related to the level of per-capita income across countries. In fact, we found a small negative correlation between 
returns to labor market experience (wage growth) and per-capita income across countries, which suggests that on the job investments in human capital are not likely to be an important source of income differences across countries.

Market structure We assume competitive markets for factor inputs and outputs. Firms take factor prices as given and maximize profits by choosing the demand for factor inputs:

$$
\max _{K, H>0}\left\{A K^{\alpha} H^{1-\alpha}-w H-(r+\delta) K\right\}
$$

Public Education Since our calibration strategy is to use cross-sectional heterogeneity within a country to restrict the parameters governing human capital accumulation, we cannot abstract from the role of public education on education and labor market outcomes. We model public education by assuming that education expenditures are subsidized at the rate $p$ per unit of schooling time. These expenditures are financed with a proportional tax $\tau$ on household's income. Public and private expenditures are perfect substitutes in the production of human capital.

Decision problem of the household All decisions of the household are made by the parent. We assume that markets are imperfect in that households cannot perfectly insure against labor-market risk and they cannot borrow. The state of a young parent is given by a triple $(z, h, q)$ : earnings ability $z$, human capital $h$, and parental transfer $q$ received from the previous household in the dynasty line. Households maximize discounted lifetime utility of all future generations in the dynasty. Young parents choose consumption $c_{y}$, assets $a_{y}^{\prime}$, time spent in school by their children $s$ (where $1-s$ is working time of the children), and resources spent on the quality of education of their children $e$. A parent who provides his child with $s$ years of schooling and a quality of education $e$ incurs expenditures of $e+(w \bar{l}-p) s$, where $w \bar{l}$ is a cost per year of education (which is assumed to depend on the market wage rate) and $p$ denotes public education expenditures (or subsidies) per year of education. We take a broad 
view of human capital and interpret the quality of education $e$ as including non-education expenditures (such as child-rearing and health care) that enhance future earnings of children. Young parents face uncertainty regarding the ability of their children $z^{\prime}$ which is realized in the second stage of the household's life cycle.

In the second stage, the household consists of a child with earnings $w h^{\prime}$ and a parent with earnings $\psi_{o} w h$. Old parents decide savings for retirement $a_{o}^{\prime}$, consumption $c_{o}$, and an intergenerational transfer $q^{\prime}$ for the next household in the dynasty. Retired people consume their savings.

The decision problem of a young household can be written using the dynamic programming language as follows:

$$
v(z, h, q)=\max _{c_{y}, e, s, h^{\prime}, a_{y}^{\prime},\left[c_{o}, c_{r}, a_{o}^{\prime}, q^{\prime}\right]\left(z^{\prime}\right)}\left\{U\left(c_{y}\right)+\beta \sum_{z^{\prime}} Q\left(z, z^{\prime}\right)\left[U\left(c_{o}\right)+\beta E v\right]\right\},
$$

subject to

$$
\begin{aligned}
c_{y}+a_{y}^{\prime}+e+(w \bar{l}-p) s & =(1-\tau)\left[\psi_{y} w h+w \Psi_{c}(1-s)+r q\right]+q, \\
c_{o}\left(z^{\prime}\right)+a_{o}^{\prime}\left(z^{\prime}\right)+q^{\prime}\left(z^{\prime}\right) & =(1-\tau)\left[\psi_{o} w h+w h^{\prime}\left(z^{\prime}\right)+r a_{y}^{\prime}\right]+a_{y}^{\prime}, \\
c_{r}\left(z^{\prime}\right) & =(1-\tau) r a_{o}^{\prime}\left(z^{\prime}\right)+a_{o}^{\prime}\left(z^{\prime}\right), \\
e+(w \bar{l}-p) s & \geq 0 \\
\Psi_{c} & =\psi_{c}\left(s^{\eta} e^{1-\eta}\right)^{\xi}, \\
h^{\prime} & =z^{\prime}\left(s^{\eta} e^{1-\eta}\right)^{\xi}, \\
a_{y}, a_{o}, q^{\prime}\left(z^{\prime}\right) & \geq 0, \quad s \in[0,1],
\end{aligned}
$$

where

$$
E v=\left[\phi\left(U\left(c_{r}\right)+v\left(z^{\prime}, h^{\prime}, q^{\prime}\right)\right)+(1-\phi) v\left(z^{\prime}, h^{\prime}, q^{\prime}+c_{r}\right)\right]
$$

The parameter $\phi$ is the probability of survival for a retired adult. Since old parents know the ability of their children when making consumption, saving, and bequest decisions, these 
choices are expressed as contingent on their children's ability $z^{\prime}$ in the dynamic programming problem of young parents.

\section{Human capital investments in a complete markets environment}

This section provides some analytical results that shed light on how the parameters of the human capital technology determine the quantitative implications of the theory. To this end, we study two simplified versions of the model economy. In both specifications we assume complete markets so that human capital investment decisions are independent of consumption decisions. The first specification assumes a deterministic ability so that dynasties face no uncertainty. We show that the parameters of the human capital technology that determine earnings inequality in the economy (across individuals with different ability) also determine the income inequality across countries (with different TFP). In particular, the quantitative implications of the theory for income inequality - within and across countries - depend crucially on the expenditure elasticity of human capital. We then show that our results extend to the complete markets economy with stochastic ability. Moreover, the cross-sectional implications of the complete market economy provide valuable insights for calibrating the benchmark economy with incomplete markets and for understanding the quantitative findings of the paper.

\subsection{Deterministic ability}

Consider a world with a large number of countries. Each country is populated by measure 1 of dynasties and is characterized by a fixed TFP level $A$, which varies across countries according to a $c d f G_{A}$ with a continuous density function. Each dynasty is characterized by a fixed ability level, which varies across dynasties according to a $c d f G_{z}$ with a continuous density function. Denote the variance of $\ln A$ and of $\ln z$ by $\sigma_{A}^{2}$ and $\sigma_{z}^{2}$. 
Capital markets are assumed to be perfect so that in equilibrium individuals make efficient investments in human capital. The attention is confined to the steady state analysis. The equilibrium interest rate is given by the individuals rate of time preference $\rho \equiv 1 / \beta-1$. Although the theory makes no predictions for the distribution of income, consumption, and wealth, it does have important implications for the variation of schooling and earnings across individuals and countries - and for the variation of output across countries.

\subsubsection{TFP elasticity of the aggregate income and human capital}

We use the notation $E_{X Y}$ to represent the elasticity of a variable $X$ with respect to $Y$. Then from (1) the elasticity of output with respect to TFP satisfies

$$
E_{Y A}=1+\alpha E_{K A}+(1-\alpha) E_{H A}
$$

Competitive factor markets imply $\rho+\delta=A \alpha\left(\frac{K}{H}\right)^{\alpha-1}$. The steady state ratio of aggregate physical to human capital stocks is given by $K / H=\left(\frac{A \alpha}{\rho+\delta}\right)^{1 /(1-\alpha)}$. Taking $\operatorname{logs}$ and differentiating with respect to $A$, gives

$$
E_{K A}=\frac{1}{1-\alpha}+E_{H A}
$$

Note that a higher level of $A$ increases capital through a higher capital to output ratio $\left(\frac{1}{1-\alpha}\right)$ and through a higher human capital $\left(E_{H A}\right)$. Human capital thus amplifies the direct effect of TFP on physical capital. Substitute (5) into (4), to obtain

$$
E_{Y A}=E_{K A}=E_{H A}+\frac{1}{1-\alpha}
$$

The first equality implies that the capital to output ratio is constant across countries and the second equality shows that the TFP elasticity of output is determined by the response of human capital accumulation $\left(E_{H A}\right)$. In order to obtain an expression for $E_{H A}$, we first study 
the decisions of individuals regarding human capital investments and we then aggregate the behavior of individuals to obtain an aggregate elasticity.

\subsubsection{Human capital investments across individuals and countries}

Next we analyze how variation in wages and variation in ability leads to different human capital investments across countries (macro elasticity) and across individuals (micro elasticity). Our goal is to isolate how the parameters of the human capital technology jointly determine the micro and macro elasticities in our model.

First, evaluate the effect of TFP on the equilibrium wage rate. Competitive markets imply $w=A(1-\alpha)\left(\frac{K}{H}\right)^{\alpha}$, which using (5) gives $E_{w A}=1+\alpha\left(E_{K A}-E_{H A}\right)=\frac{1}{1-\alpha}>1$. TFP has a direct effect on the wage rate and an indirect effect through a higher physical to human capital ratio. Next, consider the decision problem of an individual with ability $z$ in a country with a wage rate $w$. The human capital investment decision can be formulated as choosing schooling time $(s)$ and expenditures $(e)$ to maximize the present value of lifetime earnings net of education costs:

$$
\begin{gathered}
\max _{e, s, h}\left\{w(1-s) h \psi_{0}+w h \Psi-e-w \bar{l} s\right\} \\
\text { s.t. } h=z\left(s^{\eta} e^{1-\eta}\right)^{\xi},
\end{gathered}
$$

where $\Psi=\sum_{i=1}^{3} \beta^{i} \psi_{i}$ with $\psi_{i}$ 's representing the life-cycle productivity parameters described in the previous section, and $\beta=\frac{1}{1+r}$ provided $r=\rho$. The cost of schooling includes expenditures in human capital quality $(e)$, time-purchases on the market (tuition costs) per unit of schooling time $(w \bar{l})$, and foregone earnings in the first period of life $\left(s w h \psi_{0}\right)$.

Assuming an interior solution, the corresponding first order conditions are:

$$
\begin{aligned}
-w h \psi_{0}+w h_{s}\left[(1-s) \psi_{0}+\Psi\right] & =w \bar{l} \\
w h_{e}\left[(1-s) \psi_{0}+\Psi\right] & =1
\end{aligned}
$$


where $h_{s}=\frac{h}{s} \eta \xi$ and $h_{e}=\frac{h}{e}(1-\eta) \xi$. These equations can be expressed as

$$
\begin{aligned}
& z\left(s^{\eta} e^{1-\eta}\right)^{\xi}\left\{-\psi_{0}+\frac{\eta \xi}{s}\left[(1-s) \psi_{0}+\Psi\right]\right\}=\bar{l} \\
& e=\left\{w z(1-\eta) \xi\left[(1-s) \psi_{0}+\Psi\right] s^{\eta \xi}\right\}^{\frac{1}{1-(1-\eta) \xi}}
\end{aligned}
$$

We are ready to analyze how individual decisions depend on the parameters of the maximization problem. In the absence of tuition costs $(\bar{l}=0)$, it is easy to solve for $s$ from $(11)$ and verify that the optimal quantity of schooling does not vary across individuals $(z)$ and countries $(w)$. We thus maintain $\bar{l}>0$. Similarly, if the absence of education expenditures $(\eta=1)$, the quality of schooling does not vary across individuals and countries. On the contrary, when $0<\eta<1$, equations (11) and (12) imply that both quantity and quality of schooling vary across individuals $(z)$ and countries $(w)$.

Proposition 1: The theory requires $\bar{l}>0$ and $0<\eta<1$ in order to generate differences in the quantity and quality of schooling across individuals $(z)$ and countries $(A)$.

To gain further insights using simple algebra, it is convenient to set $\psi_{0}=0$. Then combining (11) and (12), taking logs, and differentiating with respect to $\ln w$, obtain the cross-country (wage) elasticity of schooling:

$$
E_{s w} \equiv \frac{\partial \ln (s)}{\partial \ln w}=\frac{(1-\eta) \xi}{1-\xi}
$$

The individual (ability) elasticity of schooling is obtained similarly, except the differentiation is done with respect to $\ln z$ :

$$
E_{s z} \equiv \frac{\partial \ln (s)}{\partial \ln z}=\frac{1}{1-\xi}
$$

The elasticity of expenditures with respect to the ability $(z)$ and the wage rate $(w)$ is obtained by differentiating (12) with respect to $x \in\{z, w\}$ :

$$
\frac{\partial \ln (e)}{\partial \ln x}=\frac{1}{1-(1-\eta) \xi}\left(1+\eta \xi \frac{\partial \ln (s)}{\partial \ln x}\right) .
$$


Using (13) and (14), variation in the schooling quality across individuals $(z)$ and countries (w) satisfies

$$
\begin{aligned}
E_{e z} & \equiv \frac{\partial \ln (e)}{\partial \ln z}=\frac{1}{1-\xi} \\
E_{e w} & \equiv \frac{\partial \ln (e)}{\partial \ln w}=\frac{1}{1-(1-\eta) \xi}\left(1+\eta \xi \frac{(1-\eta) \xi}{1-\xi}\right)
\end{aligned}
$$

\subsubsection{From micro to macro elasticities}

Building on the characterization of the individual decisions, we now focus on how changes in TFP impact aggregate variables. That is, we want to go from $E_{h w}$ to $E_{H A}$.

We first derive individual human capital elasticities. Log-differentiating (8) with respect to $\ln z$ and $\ln w$, together with (13),(14),(16) and (17), gives

$$
\begin{aligned}
E_{h w} & \equiv \frac{(1-\eta) \xi}{1-\xi} \\
E_{h z} & \equiv \frac{1}{1-\xi}
\end{aligned}
$$

Using $E_{h A}=E_{h w} E_{w A}$ and $E_{w A}=\frac{1}{1-\alpha}$, the TFP-elasticity of the individual human capital is

$$
E_{h A}=\frac{1}{1-\alpha} \frac{(1-\eta) \xi}{1-\xi}
$$

Since $E_{h A}$ does not vary across individuals, the aggregation is trivial: If two countries differ in TFP by a ratio $A_{R}$, their ratio of aggregate human capital is $H_{R}=\int\left(A_{R}\right)^{E_{h A}} d G_{z}=$ $\left(A_{R}\right)^{E_{h A}}$. We thus conclude $E_{H A}=E_{h A}$. Table 2 summarizes the mapping from the model parameters into the micro and macro elasticities.

We are now ready to explore the sensitivity of the TFP elasticity of human capital to the parameters of the human capital technology. Since $E_{h A}$ increases with the returns to scale parameter $\xi$ and decreases with the time share parameter $\eta, E_{h A}$ increases with the expenditure elasticity of human capital and is maximized when $\eta=0$ and $\xi=1$. As the 
Table 2: Elasticities for the Deterministic Model

\begin{tabular}{|c|c|}
\hline Macro & $\frac{1}{1-\alpha}$ \\
$E_{w A}$ & $\frac{1}{1-\alpha} \frac{(1-\eta) \xi}{1-\xi}$ \\
$E_{H A}=E_{h A}=E_{h w} E_{w A}$ & $\frac{1}{1-\alpha} \frac{1-\eta \xi}{1-\xi}$ \\
$E_{Y A}=E_{K A}=E_{H A}+\frac{1}{1-\alpha}$ & $\frac{(1-\eta) \xi}{1-\xi}$ \\
$E_{s w}=E_{h w}$ & $\frac{1}{1-(1-\eta) \xi}\left(1+\frac{\xi^{2} \eta(1-\eta)}{1-\xi}\right)$ \\
$E_{e w}$ & $\frac{1}{1-\xi}$ \\
\hline Micro & \\
$E_{s z}=E_{h z}=E_{e z}$ &
\end{tabular}

time share parameter $\eta$ decreases from 1 to $0, E_{H A}$ takes values in the interval $\left[0, \frac{1}{1-\alpha} \frac{\xi}{1-\xi}\right]$. For instance, if $\alpha=1 / 3$ and $\xi=0.9, E_{H A}$ takes values between 0 and 15 . Then (6) implies that the TFP-elasticity of aggregate output is between $3 / 2$ to 16.5 , depending on the time share parameter. In other words, a TFP ratio of 3 can generate differences in output per worker anywhere from a factor of 5 to 74 million. ${ }^{4}$

Proposition 2: The amplification effect of human capital, given by (20), depends crucially on the expenditure elasticity of human capital $(1-\eta) \xi$. In particular, if the expenditure share is zero $(\eta=1)$, then human capital does not amplify TFP differences across countries, no matter how close $\xi$ is to 1 .

\subsection{Stochastic ability}

Now consider an economy where individual ability evolves stochastically. First, we show that the findings of the previous section extend to the economy with stochatic ability. Second, we derive some analytical relationships to motivate our calibration strategy. These findings will illuminate the quantitative results for the benchmark economy we obtain later on.

\footnotetext{
${ }^{4}$ While $E_{h A}$ is determined both by $\eta$ and $\xi$, note that the expenditure elasticity alone provides a lower bound to the amplification effect. This is because $\eta \geq 0$ implies $(1-\eta) \xi \leq \xi$, which together with (20) and $\xi<1$ implies that $E_{h A} \in\left[\frac{1}{1-\alpha} \frac{(1-\eta) \xi}{1-(1-\eta) \xi}, \infty\right)$. On the other hand, the parameter $\xi$ implies an upper bound for $E_{h A}$ since $E_{h A}$ varies from 0 to $\frac{1}{1-\alpha} \frac{\xi}{1-\xi}$ for all feasible values of $\eta$.
} 
Assume that ability is correlated across individuals in a dynasty according to a transition function $Q\left(z_{0}, z\right)$, where $z_{0}$ denotes the ability of the parent and $z$ the ability of the children. Individuals make investment decisions before knowing the realization of a random ability shock $z$, which is distributed according to the probability measure $Q\left(z_{0}, \cdot\right)$.

Given that individuals can fully diversify all risk, the human capital investment decision can be separated from the consumption decisions. Individuals maximize the expected discounted lifetime earnings net of education costs:

$$
\max _{e, s} \int\left\{w(1-s) h \psi_{0}+w h \Psi-e-w \bar{l} s\right\} Q\left(z_{0}, d z\right)
$$

subject to (8) and given $z_{0}$. Define the conditional expectations of ability $g\left(z_{0}\right) \equiv \int z Q\left(z_{0}, d z\right)$ and human capital $\hat{h} \equiv g\left(z_{0}\right)\left(s^{\eta} e^{1-\eta}\right)^{\xi}$. Substitution of these functions into (21) makes the optimization problem for the stochastic economy identical to problem (7) for the deterministic economy, provided $z=g\left(z_{0}\right) .{ }^{5}$ Thus, in the presence of uncertainty, optimal investment decisions depend on the conditional expectations of ability, $g\left(z_{0}\right)$, instead of the realized ability $z$, but are otherwise identical to the economy with deterministic ability.

It follows that the elasticities of schooling time and expenditure with respect to wages and expected ability are also the same as in the deterministic economy (equations (13),(14), (17) and (16) hold). Moreover, schooling time and expenditures can be expressed as

$$
\begin{aligned}
& s\left(z_{0}, w\right)=c_{s} g\left(z_{0}\right)^{E_{s z}} w^{E_{s w}}, \\
& e\left(z_{0}, w\right)=c_{e} g\left(z_{0}\right)^{E_{e z}} w^{E_{e w}},
\end{aligned}
$$

where $c_{s}$ and $c_{e}$ are independent of $\left(z_{0}, w\right)$. Combining (22), (23), (8) and the expressions in Table 2 for $\left(E_{s z}, E_{s w}, E_{e z}, E_{e w}\right)$, obtain the human capital of an individual with parental

\footnotetext{
${ }^{5}$ The objective function in (21) becomes $\left\{w(1-s) \hat{h} \psi_{0}+w \hat{h} \Psi-e-w \bar{l} s\right\}$
} 
ability $z_{0}$, which is a random variable given by

$$
h=c_{h} z g\left(z_{0}\right)^{\frac{\xi}{1-\xi}} w^{\frac{(1-\eta) \xi}{1-\xi}},
$$

where $c_{h}$ is a constant (independent of $z_{0}, z$, and $w$ ) and $z$ is a random draw from the probability measure $Q\left(z_{0}, \cdot\right)$. It follows that the wage elasticity of human capital is also

identical to the one in the deterministic economy: $E_{h w}=\frac{(1-\eta) \xi}{1-\xi}$. We thus conclude that, as in the deterministic economy, the amplification of the TFP differences across countries is driven by the expenditure elasticity of human capital, i.e. Proposition 2 also holds in the stochastic-ability economy.

\subsubsection{The human capital technology and the cross-sectional restrictions of the theory}

Our results suggest that it is crucial to discipline the selection of parameters of the human capital technology. Note that these parameters $(\eta, \xi)$ cannot be calibrated independently from the stochastic process for ability $(z)$ since they jointly determine the implications of the theory (see (22) and (24)). In brief, our calibration will target data for the United States: cross-sectional evidence on schooling and earnings and the aggregate share of goods in the costs of education. Our approach of calibrating to the U.S. data rather than to the crosscountry data is motivated by the fact that countries may differ in other dimensions beside the TFP, such as public policy, which influence education decisions. In addition, we want to impose discipline on the parameters of the human capital technology using data other than the cross-country data for which the model has implications.

In motivating the calibration strategy, discussed in detail in the next section, it is useful to look at the cross-sectional implications of the complete markets model. To this end, suppose ability is not correlated across generations (i.e. ability is a random iid draw). In this case, the expected ability $g\left(z_{0}\right)$ does not vary across individuals, and hence $(22)$ implies no cross- 
sectional variation in schooling. Thus, ability shocks need to be serially correlated for the theory to be consistent with the cross-sectional evidence on schooling. Moreover, if ability shocks were perfectly correlated across generations, then $z=g\left(z_{0}\right)=z_{0}$ and (24) implies that there is no variation in earnings across individuals with the same level of schooling. To sum up, ability shocks need to be imperfectly correlated across generations for the theory to be consistent with the cross-sectional evidence on schooling and earnings.

To understand how earnings vary with the expected ability, integrate (24) with respect to $Q\left(z_{0}, \cdot\right)$ to obtain the average human capital of individuals with the expected ability $g\left(z_{0}\right)$ and, hence, with the same level of schooling,

$$
\hat{h}\left(z_{0}, w\right)=c_{h} g\left(z_{0}\right)^{\frac{1}{1-\xi}} w^{\frac{(1-\eta) \xi}{1-\xi}} .
$$

For a fix $w$, the variance of the mean earnings in the economy satisfies $\operatorname{var}(\ln \hat{h})=\left(\frac{\sigma_{g(z)}}{1-\xi}\right)^{2}$, where $\sigma_{g(z)}^{2}$ denotes the cross-sectional variance of the expected ability. Two important observations are immediate from this expression: First, the variation in earnings increases with $\xi$ - the returns to scale in the human capital technology. Second, the variance in earnings is independent of the time share parameter $\eta$.

The latter observation is useful for understanding some experiments that we conduct in the next section of the paper. In these experiments we perform a sensitivity analysis that consists of varying the target for the share of time inputs in the aggregate cost of education and recalibrating the model economy. In this way we obtain alternative calibrated model economies that differ in the time share parameter. As we later confirm, all the model economies match the calibration targets well. We shall thus conclude that the identification of the time share parameter comes primarily from the target for the share of time inputs in the aggregate cost of education and not from the cross-sectional restrictions of the theory, which is consistent with the second observation made above.

It is also interesting to evaluate the complete markets economy in terms of its predictions 
for the quality of immigrants by country of origin. Consider an economy that has a large number of immigrants born in two countries that differ in their TFP. We assume that, conditional on a schooling level, immigration is a random draw from the population in each of the countries, and that immigrants were educated in their country of origin. Denote the ratio of wage rates between the two countries by $w_{R}$. Then $(22)$ implies that the ratio of expected ability is

$$
g_{R}=\left(\frac{1}{w_{R}}\right)^{\frac{E_{s w}}{E_{s z}}}=\left(\frac{1}{w_{R}}\right)^{(1-\eta) \xi} .
$$

Using (25) and (26), the ratio of the average human capital for the two groups of immigrants satisfies

$$
\hat{h}_{R}=g_{R}^{\frac{1}{1-\xi}} w_{R}^{\frac{(1-\eta) \xi}{1-\xi}}=\left(\frac{1}{w_{R}}\right)^{\frac{(1-\eta) \xi}{1-\xi}} w_{R}^{\frac{(1-\eta) \xi}{1-\xi}}=1
$$

That is, the theory predicts that the quality of immigrants does not change with the per capita income of the immigrant's country of origin - a prediction that is inconsistent with the evidence in Borjas (1997). We will later show that our benchmark economy with incomplete markets makes a successful step toward replicating Borjas' findings, and the degree of the success is determined by the time share parameter.

Next, we show that variation in the average years of schooling across countries is closely tied to the expenditure share in the human capital technology. Integrate $(22)$ over $G_{z}$ and take logs to obtain $\ln \int s(z, w) G_{z}(d z)=c_{w}+E_{s w} \ln w=c_{w}+\frac{(1-\eta) \xi}{1-\xi} \ln w$, for some constant $c_{w}$. Notice that $\ln w=c_{y}+\frac{1-\xi}{1-\eta \xi} \ln Y$, for some constant $c_{y} \cdot{ }^{6}$ Combining the last two expressions we obtain

$$
\ln \int s(z, w) G_{z}(d z)=c+\frac{(1-\eta) \xi}{1-\eta \xi} \ln Y
$$

Thus, the schooling-income elasticity across countries is equal to $\frac{(1-\eta) \xi}{1-\eta \xi}$, which is a decreasing function of the time share parameter $\eta$. In the next section, we will show that this finding extends to the benchmark economy with incomplete markets: the cross-country schooling

\footnotetext{
${ }^{6}$ This expression is obtained as follows: First, $E_{w A}=\frac{1}{1-\alpha}$ implies $\ln w=c_{w}+\frac{1}{1-\alpha} \ln A$, for some $c$. Second, $E_{Y A}=\frac{1}{1-\alpha} \frac{1-\eta \xi}{1-\xi}$ implies $\ln Y=c+\frac{1}{1-\alpha} \frac{1-\eta \xi}{1-\xi} \ln A$.
} 
elasticity with respect to income declines with $\eta$.

Proposition 3: The economy with stochastic abilities and complete markets exhibits the same TFP elasticities of output, human capital, and schooling as the deterministic economy. The cross-sectional variances of earnings and schooling are driven by the stochastic process on ability and the returns to scale in the human capital technology. In particular, the time share parameter does not have consequences for the cross-sectional variances. The complete market economy counterfactually predicts that the quality of immigrants is independent of the per capita income of the immigrant's country of origin.

\subsection{Relative productivity in the investment sector}

We now assume that countries differ in the relative productivity of the investment sector. To this end, assume that the production of investment goods requires the use of a technology that converts the consumption good into the investment good. Denoting the TFP in the investment good sector by $A_{k}$, we have $K_{t+1}=(1-\delta) K_{t}+A_{k} X_{t}$, where $X_{t}$ is the gross investment in period $t$. It is easy to see that $A_{k}$ determines the steady-state ratio of physical capital to human capital and, thus, the long run wage rate in the economy. Note that one unit of consumption can be transformed into $A_{k}$ units of capital which in turn can be transformed into $A_{k} \alpha A\left(\frac{K}{H}\right)^{\alpha-1}$ units of the consumption good. In steady state, the return

on capital $A_{k} \alpha A\left(\frac{K}{H}\right)^{\alpha-1}=\rho+\delta$, where $\rho$ is the interest rate (given by the rate of time preference). Solving for $K / H$, obtain

$$
\frac{K}{H}=\left(\frac{\alpha A_{k} A}{\rho+\delta}\right)^{\frac{1}{1-\alpha}}
$$

The steady state wage rate then satisfies $w=(1-\alpha) A\left(\frac{K}{H}\right)^{\alpha}$, which, using $(27)$, can be expressed as $w=c_{w} A^{\frac{1}{1-\alpha}} A_{k}^{\frac{\alpha}{1-\alpha}}$, where $c_{w}$ is independent of $A$ and $A_{k}$. Thus, the $A_{k}$ elasticity of wages is given by

$$
E_{w A_{k}}=\frac{\alpha}{1-\alpha} .
$$


Then the amplifier effect of the producitivity differences in the investment sector on human capital differences across countries is determined by the elasticity $E_{h A_{k}}=E_{h w} E_{w A_{k}}$, where $E_{h w}$ is given by (18) and $E_{w A_{k}}-$ by (28).

Proposition 4: Assume that countries differ in the relative productivity of the investment good sector. The amplification effect of human capital accumulation is driven by the wage elasticity of human capital.

\section{Calibration}

As discussed in the previous section, the aggregate implications of TFP differences across countries in our model hinge on the parameters determining human capital accumulation. Our calibration strategy is to restrict these parameters using cross-sectional heterogeneity of schooling and earnings in the data for the United States.

\subsection{Parameters and targets}

We calibrate our benchmark economy to data for the United States. The model period is 16 years. Because we are interested in comparisons across countries, the level of technology in the benchmark economy is effectively a normalization. Therefore, we set $A=A_{k}=1$. The mapping between parameters and targets in the data is multidimensional, and we thus solve for parameter values jointly. We divide the discussion of calibration into parameters that relate to preferences, demographics, and production of goods and parameters that relate to human capital accumulation. A summary of parameter values and data targets is provided in Table 3.

Preferences, demographics, and production of goods We set the relative-risk-aversion parameter $\sigma$ to 2. There is not a direct empirical counterpart for this parameter in the empirical literature since our model period is 16 years and there is an infinite inter-temporal 
Table 3: Parameters and Data Targets

\begin{tabular}{|lcc|lcc|}
\hline \multicolumn{1}{|c}{ Parameter } & & Value & Target & U.S. & Model \\
\hline CRRA & $\sigma$ & 2 & Empirical literature & - & - \\
Discount factor & $\beta^{1 / 16}$ & 0.94 & Interest rate (\%) & 5 & 5 \\
Survival probability & $\phi$ & 0.4 & Life expectancy at birth (years) & 76 & 76 \\
Capital share & $\alpha$ & 0.33 & Capital income share & 0.33 & 0.33 \\
Annual depreciation & $\delta$ & 0.07 & Investment to output & 0.2 & 0.2 \\
H.C. time share & $\eta$ & 0.66 & Share of labor in total ed. cost & 0.9 & 0.9 \\
H.C. RTS & $\xi$ & 0.79 & Mincer returns to schooling (\%) & 10 & 10 \\
Schooling cost & $\bar{y}$ & 0.89 & Average years of schooling & 12.9 & 12.9 \\
Tax rate on income & $\tau$ & 0.039 & Public Education (\% of GDP) & 3.9 & 3.9 \\
Child's productivity & $\psi_{c}$ & 0.13 & Percentage with college degree & 24 & 24 \\
Young adult's productivity & $\psi_{y}$ & 1.4 & Relative earnings & 1.4 & 1.4 \\
Old adult's productivity & $\psi_{o}$ & 1.08 & Relative earnings & 1.57 & 1.57 \\
Ability variance & $\sigma_{z}$ & $(0.51)^{2}$ & VAR(log-earnings) & 0.36 & 0.36 \\
Ability correlation & $\rho_{z}$ & 0.17 & CORR(log-earnings) & 0.5 & 0.5 \\
\hline
\end{tabular}

substitution of consumption within a period. However, we view a value of $\sigma$ that is in the range of values considered in quantitative studies with heterogeneous agents. (See Keane and Wolpin (2001) and Restuccia and Urrutia (2004) for discussions of these estimates.) The discount factor $\beta$ is set to target an annual interest rate of 5 percent which is roughly the return on capital in the U.S. economy (see Poterba (1997)). ${ }^{7}$ In our model, retired adults live up to the age of 85. The National Center for Health Statistics (2004) reports that in 1990 the average life expectancy at birth in the United States was 76 years. Therefore, we calibrate the probability of survival for retired adults $(\phi)$ to 0.4 so that the life expectancy at birth in our model matches 76 years. The capital-share parameter is set to 0.33 , consistent with the capital income share in the U.S. economy from the National Income and Products Accounts. The depreciation rate $\delta$ is selected to match an investment to output ratio of 20 percent as documented in the Economic Report of the President (2004). ${ }^{8}$

\footnotetext{
${ }^{7}$ Average return on non-financial corporate capital net of taxes in 1990-96.

${ }^{8}$ We obtain a similar target if instead we take the average of the investment to output ratio in the PWT6.1 for the period 1990 to 1996, see Heston, Summers, and Aten (2002).
} 
Human capital accumulation Recall that the human capital technology is given by $h^{\prime}=z^{\prime}\left(s^{\eta} e^{1-\eta}\right)^{\xi}$, where $s$ denotes schooling time and $e$ denotes educational expenditures. We need to specify two elasticity parameters: $\eta$ and $\xi$. Ability follows an $A R(1)$ process (in $\operatorname{logs})$ :

$$
\log \left(z^{\prime}\right)=\rho_{z} \log (z)+\epsilon_{z},
$$

where $\epsilon_{z} \sim N\left(0, \sigma_{z}\right)$. In our computations, we approximate this stochastic process with a discrete first-order Markov chain that takes 7 possible values for ability $z$. We use the approximation procedure in Tauchen (1986) to compute transition probabilities. This procedure involves selecting two additional parameter values: $\rho_{z}$ and $\sigma_{z}$. There are five additional parameters affecting human capital accumulation: Schooling cost $\bar{l}$, tax rate on income $\tau$ (that in equilibrium determines public education subsidies $p$ ), and life-cycle productivity parameters $\left(\psi_{c}, \psi_{y}, \psi_{o}\right)$, setting the relative labor earnings of children, young adults, and old adults. Our calibration procedure restricts the values of these 9 parameters so that the equilibrium of the model matches the following 9 targets from the U.S. data:

1. Intergenerational correlation of log-earnings of 0.5 from Mulligan (1997). (See also excellent surveys of the empirical literature on the intergenerational correlation of earnings by Stokey (1998) and Solon (1999))

2. Variance of log permanent earnings of 0.36 (see Mulligan $(1997,1999)$ )

3. Average years of schooling of 12.9 from the U.S. Department of Education (2004) in 1990. (See also Barro and Lee (1996).)

4. Fraction of individuals with a college degree or more of 24 percent from the Historical Tables of the U.S. Census Bureau (2004).

5. Public education expenditures as a fraction of GDP of 3.9 percent from the Statistical Abstract of the United States (1999). In computing this statistic in the data, we treat as public expenditures all state and federal expenditures. We exclude public 
local expenditures in education because these expenditures are closely tied to property values and therefore to the income of parents. (See Restuccia and Urrutia (2004) for a discussion.)

6. The ratio of earnings for full-time, year-round workers of ages 35-54 to ages 25-34 of 1.40 in 2003 from the U.S. Census Bureau, Historical Income Tables.

7. The ratio of earnings for full-time, year-round workers of ages 55-64 to ages 25-34 of 1.57 in 2003 from the U.S. Census Bureau, Historical Income Tables.

8. Mincer returns to schooling of 10 percent. Heckman et al. (2005) report a Mincer return of between 10 to 13 percent during the period 1980 to 1990. Psacharopoulos (1994) estimates a Mincer return of 10 percent for the United States for the period 1990-95. Because Psacharopoulos also provides data on Mincer returns for a large set of countries, we follow Bils and Klenow (2000) in using Psacharopoulos' estimate for the U.S. economy. In the benchmark economy, we measure returns to education by regressing log-wages on years of education:

$$
\log \left(w h_{i}^{\prime}\right)=b_{0}+b_{1}\left(16 s_{i}\right)+u_{i}
$$

where $b_{1}$ gives the Mincer return.

9. The share of labor inputs in the total cost of investment in education of 90 percent according to Kendrick (1976) and the U.S. Department of Education (1996).

\subsection{The benchmark economy}

The benchmark economy matches all the calibration targets well (see Table 3). In particular, it successfully replicates the U.S. cross-sectional data on schooling (Mincer return, average years of schooling, fraction of college-educated individuals), earnings (variance and intergenerational correlation of earnings), and the share of labor inputs in total education costs. We 
now show that the model is consistent with several dimensions of heterogeneity in the data that were not targeted in the calibration. We conclude that the model is a good quantitative theory of within-country heterogeneity.

Distribution of Schooling According to the U.S. Department of Education (2004) the proportion of people in 1990 between 25 and 34 years of age (all sexes and races) with primary schooling (1st to 8th grade) as their highest education attainment was 4 percent, with secondary schooling (9th to 12 th grade) - 50 percent, and with college education (4 years of college or more) -24 percent. Our model matches these statistics reasonably well as documented in Table $4 .^{9}$

Table 4: Education and Earnings - Model and Data

\begin{tabular}{lcccccc}
\hline & \multicolumn{2}{c}{ Schooling Dist. } & \multicolumn{2}{c}{ Rel. Earnings } & \multicolumn{2}{c}{ Mincer Ret.(\%) } \\
& Model & Data & Model & Data & Model & Data \\
\hline Primary & 0.08 & 0.04 & 0.66 & 0.62 & 15.6 & 21.8 \\
Secondary & 0.28 & 0.50 & 1.00 & 1.00 & 9.3 & 11.5 \\
College & 0.24 & 0.24 & 1.78 & 1.70 & 10.3 & 9.6 \\
\hline
\end{tabular}

Mincer returns data from Willis (1986).

Schooling and earnings The benchmark economy matches the joint distribution of earnings and schooling in the data well. According to the U.S. Department of Education (2004), in 1998 males in the U.S. with college education earn (on average) 70 percent more than high-school graduates. This earning ratio is 1.78 in the benchmark economy. Similarly, the earnings ratio between individual with primary education and secondary education is .62 in the U.S. data and it is .66 in the model economy (see Table 4). Recall that the the calibration targeted the average Mincer returns to education. Nonetheless, the benchmark economy is also consistent with the fact that in the data Mincer returns are substantially higher at low

\footnotetext{
${ }^{9}$ We note, however, that time in school is a continuous variable in our model, making its comparison with the data non trivial. In particular, the distribution of schooling in the data has clear spikes at levels of education where an educational degree is completed.
} 
levels of schooling. In the benchmark economy and in the U.S. data, earnings vary not only across individuals with different years of schooling but also across individuals with the same level of schooling. To evaluate the importance of earnings inequality within schooling groups in the benchmark economy, we simulate individual level data on schooling and earnings. We then regress log earnings on schooling years and obtain an $R^{2}$ of only 26.5 percent. Thus, the regression results imply that schooling accounts for a low fraction of the variance in earnings across individuals which is consistent with the findings in the labor literature for the United States (see for instance Neal and Johnson (1996)).

Expenditures on education The share of GDP spent on education increases with the returns to scale parameter in the human capital production function as discussed in our calibration section. In light of that discussion, it is interesting to compare the proportion of GDP in the form of educational expenditures in our model with the data. Haveman and Wolfe (1995) report that expenditures on children aged 0-18 are as large as 14.5 percent of GDP. This share includes not only public investment, but also private costs, such as food, housing, transportation and foregone parental earnings in child care. When we exclude foregone parental earnings from Haveman and Wolfe's numbers we obtain 12.6 percent. In

our model, total education expenditures correspond to $(e+w \bar{l} s)$ aggregated over all people. In the benchmark economy and using this formula, total expenditures on education amount to 12 percent of GDP, a figure close to Haveman and Wolfe's estimate.

\section{$5 \quad$ Quantitative results}

We use our quantitative theory to assess the aggregate and distributional consequences of TFP differences across countries. Changes in TFP affect human capital accumulation since human capital investment requires goods in our calibrated model economy (see the discussion in Section 3). The question we address in this section is about the quantitative magnitude of this effect. We find that TFP has a large effect on human capital accumulation and output 
even though goods represent only a small proportion of the total cost of education in our benchmark economy (around 10 percent).

\subsection{Aggregate implications}

We assume that countries are identical in terms of preferences and technologies except for their level of TFP in the production of goods. Then, by construction, all cross-country differences in output per worker in our model are generated by differences in TFP. Since TFP has an indirect effect on output per worker through factor accumulation, we investigate the degree to which the impact of TFP on output per worker is amplified by factor accumulation and the relative contribution of physical and human capital accumulation. To illustrate the magnitude of this amplification effect we compare aggregate statistics from these economies. Relative to the benchmark economy, economies with relative TFP levels of $1 / 2$ and 1/3 exhibit relative output per worker of $1 / 6$ and $1 / 21$ and relative human capital of $1 / 3$ and 1/4. Low relative TFP leads to low average years of schooling and high Mincer return. In Table 5 we compare summary aggregate statistics for economies that differ in their TFP.

Table 5: Aggregate Implications of TFP Differences in the Model

\begin{tabular}{lccc}
\hline Relative TFP $(A)$ & 1 & $1 / 2$ & $1 / 3$ \\
Rel. $Y$ & 1 & $1 / 6$ & $1 / 21$ \\
Rel. $H$ & 1 & $1 / 3$ & $1 / 4$ \\
$K / Y$ & 2.8 & 2.7 & 2.7 \\
Average Years of Schooling & 12.9 & 7.1 & 4.3 \\
Returns to Schooling (\%) & 10.0 & 14.5 & 22.6 \\
\hline
\end{tabular}

Amplification effect Unlike the results in Section 3, the TFP amplification effect in the benchmark economy cannot be characterized with an analytical expression. However, there is a simple way of measuring it using the simulated cross-country data. First, note that changes in TFP induce a linear relationship (with slope equal to 1) between log output and log physical capital. This result is a consequence of the fact that in Bewley-type economies 
(dynastic economies with uninsurable idiosyncratic risk), the equilibrium interest rate is close to the rate of time preference (see for instance Aiyagari (1994) and Fuster (2000)). As a result, in equilibrium the marginal product of capital is close to the rate of time preference plus the depreciation rate of capital, i.e., $\frac{\partial y}{\partial k}=\alpha \frac{y}{k} \approx \rho+\delta$. Using this relationship to solve for $k$ as a function of output we obtain $k=c_{k} y$ for some constant $c_{k}$. Second, as indicated in Figure 1, the model implies a linear relationship between log human capital and log output as TFP varies across economies, but the slope of this relationship is less than one. Using this observation, we write human capital as a function of output as $\log (h)=c_{h}+\gamma \log (y)$, which implies that $h=\exp \left(c_{h}\right) y^{\gamma}$. Substituting the expressions derived for $k$ and $h$ (in terms of $y$ ) in the production function of goods and solving for $y$ we obtain

$$
y=c_{y} A^{\frac{1}{(1-\alpha)(1-\gamma)}}
$$

for some constant $c_{y}$. Then, the TFP elasticity of output per worker in our model is $\frac{1}{(1-\alpha)(1-\gamma)}$. In the benchmark economy, $\alpha=0.33$ and $\gamma=0.46$ (as indicated by the slope coefficient in Figure 1). As a result, the TFP elasticity of output per worker is equal to 2.77. It follows that if TFP differs by a factor of 2 between two economies, the model implies that their output per worker would differ by a factor of $2^{2.77}=6.8$. Another way of expressing this result is to compute the TFP differences required in the model to generate a given difference in output per worker between two countries. From equation (29), the ratio of output per worker between any arbitrary economies $i$ and $j$ is related to their relative TFP levels:

$$
\frac{y_{i}}{y_{j}}=\left(\frac{A_{i}}{A_{j}}\right)^{\frac{1}{(1-\alpha)(1-\gamma)}}
$$

Using an elasticity of 2.77 from our previous calculations, it follows that an output ratio of 20 can be generated by a TFP ratio of 2.94 . We thus conclude that our calibrated model implies a large amplification effect of TFP differences across countries. Moreover, we note that the amplification effect provided by physical capital is $\frac{1}{1-\alpha}=1.49$ and the one provided 
by human capital is $\frac{1}{1-\gamma}=1.85$. Human capital thus represents an important source of amplification.

Human capital and mincer returns To the extent that schooling quality affects the intercept term in a Mincer regression (as discussed in Section 2), the use of estimated Mincer returns to measure human capital stocks across countries may underestimate differences in human capital across countries. Since Mincer returns are frequently used to measure human capital in growth accounting exercises, it is of interest to assess the importance of this bias using our calibrated model economy. To this end, we use Mincer returns to measure human capital across model economies that differ in their TFP levels. We consider countryspecific Mincer returns and allow each year of schooling to have a different return, depending on whether the year of schooling corresponds to primary, secondary, or college education. We add across people using the population share in each schooling category to obtain an aggregate measure of human capital per worker. We report results in Table 6. Whereas the economy with relative TFP of $1 / 3$ has a human capital equal to 0.25 (relative to the benchmark economy), the Mincer measure would imply a human capital of 0.5 (half the difference in our model). We conclude that Mincer returns underestimate human capital differences across countries by a large margin.

Table 6: Human Capital across Economies

\begin{tabular}{lccc}
\hline Relative TFP & 1 & $1 / 2$ & $1 / 3$ \\
\hline (1) Human Capital Ratio & 1 & 0.45 & 0.25 \\
(2) Mincer H.C. Ratio & 1 & 0.69 & 0.51 \\
Ratio of (2) to (1) & 1 & 1.5 & 2.0 \\
\hline
\end{tabular}

Schooling quality Our quantitative theory implies that schooling quality is important for understanding differences in human capital and output per worker across countries. This result raises the question: Are the schooling-quality differences implied by our theory reasonable? While there are no reliable cross-country measures of schooling quality, the literature 
has used the empirical evidence on earnings of immigrants as an indirect approach to measuring human capital differences across countries. Therefore, it is of interest to compare our findings with those of Borjas (1987). Looking at immigrant wages in the United States, Borjas estimates that, on average, the wage that a worker with a given amount of education earns in the United States is 0.12 percent higher when the income per person in the immigrant's country of origin is 1 percent higher.

Table 7 shows that the average earnings of a person in the benchmark economy is between 3.5 and 4 times the average earnings of a similar worker in the economy with relative TFP level of $1 / 2$ (depending on the schooling level of the person) and it is more than 7 times the earnings of an equally educated worker in a country with relative TFP level of 1/3. The earnings ratio is largest for people with primary education. The bulk of cross-country earnings differences can be attributed to differences in relative prices. If a person from the economy with relative TFP of $1 / 2$ were to migrate to the benchmark economy, the wage rate of this person would increase by a factor of 2.8. If the immigrant comes from an economy with relative TFP of $1 / 3$, his wage rate would increase by a factor of 5.2. Our model is thus consistent with the observed migration pressures from poor to rich countries. On average, immigrants in the benchmark economy would not earn the same as natives with the same school years because of the differences in the quality of schooling (as captured by the expenditure on education goods). Native workers with primary and college education in the benchmark economy earn between 20 to 40 percent more than potential immigrants with same level of schooling and born in the economy with relative TFP of $1 / 2$. The information in Table 7 can be used to obtain an estimate of the income elasticity of schooling quality (by schooling level) across countries as follows:

$$
\eta_{\text {quality } y}=\frac{\log \left(\frac{H_{1}}{H_{j}}\right)}{\log \left(\frac{Y_{1}}{Y_{j}}\right)},
$$

where $H_{1}$ and $Y_{1}$ stand for human capital and per capita income in the benchmark economy 
(relative $\mathrm{TFP}$ of 1 ) and $j$ represents a country with relative $\mathrm{TFP}$ of $j$. When considering potential immigrants with secondary education from economies with relative TFP of $1 / 2$ and $1 / 3$, we obtain schooling-quality elasticities between 0.10 and 0.11 which are close to the 0.12 estimate in Borjas (1987).

Table 7: Quality of Education

\begin{tabular}{|c|c|c|c|c|}
\hline Education Level & Earnings Ratio* & Wage Ratio* & Quality Ratio* & Elasticity \\
\hline \multicolumn{5}{|c|}{ Panel A: relative $\mathrm{TFP}=1 / 2$} \\
\hline Primary & 4.0 & 2.8 & 1.4 & 0.18 \\
\hline Secondary & 3.5 & 2.8 & 1.2 & 0.10 \\
\hline Some college & 3.5 & 2.8 & 1.2 & 0.10 \\
\hline \multicolumn{5}{|c|}{ Panel $\mathrm{B}$ : relative $\mathrm{TFP}=1 / 3$} \\
\hline Primary & 10.6 & 5.2 & 2.0 & 0.23 \\
\hline Secondary & 7.4 & 5.2 & 1.4 & 0.11 \\
\hline Some college & 7.1 & 5.2 & 1.4 & 0.11 \\
\hline
\end{tabular}

${ }^{*}$ Ratio of benchmark economy to economies with relative TFP of $1 / 2$ and $1 / 3$.

Amplification effect with efficient investments Due to incomplete markets, investments in human capital are not necessarily efficient in the benchmark economy. It is possible that investments are more inefficient in poor countries relative to rich. To what extent is the large TFP amplification effect in the benchmark economy driven by the market incompleteness? To assess the role of inefficient investments, we consider a complete markets counterpart of the benchmark economy, as described in section 3.2. We then evaluate the quantitative impact of changing TFP in this economy with efficient investments. We find that the TFP elasticity of output is 2.85 , which is close to 2.77 found for the benchmark economy. Thus, the large amplification effect is driven by the TFP effect on the relative prices of the human capital inputs and not by the inefficiency of investments in poor countries. 


\subsection{Sensitivity analysis}

Our baseline calibration targeted an expenditure share of time inputs of 90 percent as reported by Kendrick (1976). We acknowledge that, despite Kendrick's careful analysis, it may be difficult to accurately measure inputs into human capital accumulation. Since the magnitude of our quantitative results hinge on the importance of time inputs, a sensitivity analysis along this dimension is warranted. ${ }^{10}$ To this end, we consider three alternative calibrations to our benchmark economy. In all the calibrated economies, we maintain the calibration targets of our benchmark economy except for the share of time inputs in education costs, which we set at 85, 95, and 100 percent (instead of 90 percent in the baseline calibration). Our goal is to evaluate the effects of TFP under different assumptions about the importance of time inputs in human capital accumulation. We then use data to discriminate among the alternative specifications.

The three calibrated model economies do as well as the benchmark economy in matching the targets discussed in section 4 (see Table 3). ${ }^{11}$ In other words, all the economies match the data targets well, including the distributional statistics. Therefore, the economies considered are equally good quantitative theories of the U.S. income distribution (as we have anticipated in Section 3). However, there are a number of dimensions where these economies perform differently. We discuss these differences in detail.

To start, we compute the TFP elasticity of output per worker in each of the calibrated model economies and report the results in Table 8 . When human capital requires only time inputs, physical capital is the only source of amplification, and it implies a TFP elasticity of 1.49. When the share of time inputs is 95 percent, the TFP elasticity of income is 1.84 . This statistic increases to 2.8 in our baseline calibration and to 3.63 when time inputs represent 85 percent. Given these elasticity estimates, the amplification effect of TFP differences

\footnotetext{
${ }^{10}$ There is a related discussion in the taxation literature where the tax effect on human capital accumulation hinges on the importance of goods in the production of human capital. For instance, see Trostel (1993) and Davies and Whalley (1989).

${ }^{11}$ The parameter values needed to match the targets are available from the authors upon request.
} 
varies substantially across economies. A factor of 3 difference in TFP implies a factor of 5.1 difference in output per worker in the specification with no goods inputs, whereas it implies a factor of 54 difference in output per worker when the share of time inputs is 85 percent. To put it differently, the TFP ratio needed to generate an output ratio of 20 between two economies is 7.5 in the time-only economy, 2.9 in the baseline calibration, and 2.3 when time inputs are 85 percent.

Table 8: Time Share and Amplification

\begin{tabular}{lcccc}
\hline & \multicolumn{4}{c}{ Time-share } \\
& 100 & 95 & 90 & 85 \\
\hline TFP Elasticity & 1.49 & 1.84 & 2.77 & 3.63 \\
Output Ratio & 5.1 & 7.6 & 20.8 & 54.0 \\
TFP Ratio & 7.5 & 5.1 & 2.9 & 2.3 \\
Schooling-Quality Elasticity: & & & & \\
$\quad$ Primary & 0 & 0.08 & 0.18 & 0.30 \\
Secondary & 0 & 0.07 & 0.10 & 0.16 \\
\hline
\end{tabular}

Given a TFP elasticity of output per worker, the output ratio is the one implied by a factor of 3 difference in TFP, and the TFP ratio is the one required to produce a factor of 20 difference in output per worker. The schooling-quality elasticity is computed using data for the economies with relative TFP of 1 and $1 / 2$.

We discriminate among the calibrated model economies as follows. For each of the specifications, we obtain observations for average years of schooling and output per worker by simulating economies that vary in their relative levels of TFP. In Figure 2, we plot cross-country data on schooling and income, taken from Barro and Lee (1996) and Heston, Summers, and Aten (2002), together with data generated by simulating the calibrated model economies. We find that the specification with a time share of 100 percent implies that average years of schooling do not vary with income, an implication that is at odds with the cross-country data. Intuitively, when human capital only requires time inputs, a change in TFP affects equally the benefits and costs of human capital accumulation. When human capital requires goods, however, an increase in TFP increases the benefits proportionally 
more than the costs of human capital accumulation, leading to an increase in the average years of schooling. Figure 2 also reveals that our baseline calibration (time share of 90 percent) does a good job of reproducing the observed pattern between schooling and income across countries. The economy with a time share of 85 percent also does a good job of reproducing this pattern.

In Figure 3, we plot cross-country data on Mincer returns and schooling, as reported in Psacharopoulos (1994). Note that Mincer returns tend to be low in countries with high average years of schooling. Our simulations reveal that goods inputs in human capital are needed to match the negative association between average years of schooling and Mincer returns across countries. Our baseline calibration does a good job of reproducing the pattern in the data. However, the economies with a time share of 85 and 95 percent also do a good job of reproducing this pattern. The time-only model implies that average years of schooling and Mincer returns do not vary across economies, an implication that is inconsistent with the cross-country data.

Goods inputs in human capital accumulation are also necessary for generating schoolingquality differences across countries. Since in the time-only economy there are no crosscountry differences in schooling quality, potential immigrants would earn the same amount as natives regardless of their country of origin, an implication that is inconsistent with the empirical findings of Borjas (1987) and Hendricks (2002) on the relative earnings of immigrants. Recall that, using data from immigrants, Borjas estimated an income elasticity of schooling quality of 0.12 . Table 8 reveals that the specification with a time share of 95 percent generates too little cross-country differences in schooling quality relative to Borjas' estimate. In this economy, the schooling-quality elasticity for people with secondary education is 0.07 , which is substantially lower than the 0.12 value estimated by Borjas. ${ }^{12}$ In our baseline calibration, with a time share of 90 percent, the schooling elasticity of income for people with secondary education is 0.10 , a value close to the 0.12 estimate. When the time

\footnotetext{
${ }^{12}$ Recall that most immigrants in the United States have a higher level of education than primary education.
} 
share is 85 percent, the schooling elasticity of income is 0.16 . Overall, we conclude that the data seems to be consistent with a time share closer to 90 percent than to 85 or 95 percent.

\subsection{Literature discussion}

We discuss our findings relative to important papers in the literature. In particular, we relate our results with those of Bils and Klenow (2000) [hereafter BK], Mankiw, Romer, and Weil (1992) [hereafter MRW], Manuelli and Seshadri (2005) [hereafter MS], and Hendricks (2002).

BK argue that MRW may have overstated the importance of human capital in accounting for cross-country income differences by focusing on a one-sector model with no distinction between the production of goods and human capital. Since, according to Kendrick (1976) study, time inputs represent 90 percent of the total costs of human capital accumulation, BK consider a two-sector model in which the production of human capital only requires time inputs. Given that in fact education does require some goods (such as computers, books, buildings, paper, and pencils) the following question arises: Is it important to take goods inputs into account when evaluating the consequences of TFP differences across countries? Our findings could not be more striking. By calibrating our benchmark economy to the estimates in Kendrick (1976), with goods accounting for only 10 percent of the cost of human capital investment, we find that human capital still implies a large amplification effect of TFP differences across countries. In fact, the amplification effect in our model is larger than the one implied in MRW.

MRW consider a one-sector growth model with $Y=C+I_{K}+I_{H}=A K^{\alpha} H^{\beta} L^{1-\alpha-\beta}$, where $\alpha=0.30$ and $\beta=0.28$. Then, the ratio of output per worker across countries differing in TFP can be expressed as:

$$
\frac{y_{h}}{y_{l}}=\frac{A_{h}}{A_{l}}\left(\frac{A_{h}}{A_{l}}\right)^{\frac{\alpha}{1-\alpha-\beta}}\left(\frac{A_{h}}{A_{l}}\right)^{\frac{\beta}{1-\alpha-\beta}}=\left(\frac{A_{h}}{A_{l}}\right)^{\frac{1}{1-\alpha-\beta}} \text {, }
$$


where the subscripts $h$ and $l$ stand for high and low TFP. In MRW, differences in TFP are amplified by a factor of $\frac{1}{1-\alpha-\beta}=\frac{1}{1-0.30-0.28}=2.38$. Thus, the amplification effect in our baseline calibration is 16 percent larger than the one implied by MRW. This finding may seem paradoxical: While MRW advocate that factor accumulation can account for most of the cross-country income differences, we find that TFP differences of a factor of 3 are needed for explaining the large variation of per capita income across countries. How can we reconcile these findings? The explanation is, as pointed by Klenow and Rodriguez-Clare (1997), that MRW overstate the cross-country variation in human capital when doing their accounting exercise. $^{13}$

MS use a calibrated model economy to evaluate the importance of human capital for understanding cross-country income differences. Their approach differs from ours in that they use a representative-agent life-cycle model. They assume that all wage growth over the life cycle is due to investment in human capital rather than capital deepening or technological progress. They calibrate the parameters of the human capital technology to match the age profile of wages in the data. This produces a TFP elasticity of output per worker of 6.6, which is substantially larger than the 2.77 elasticity in our baseline calibration. ${ }^{14}$ The discrepancy between these elasticities is not minor: While MS find that factor of 20 differences in output per worker can be explained with a TFP difference of 60 percent, our results point to a TFP difference of 200 percent. Alternatively, an amplification effect of 2.77 in our baseline calibration implies that an annual rate of TFP growth of 0.65 percent accounts for the postwar output growth in the United States (about 1.8 percent a year), whereas the amplification effect found by MS requires a much lower annual rate of technological progress (0.27 percent).

The sensitivity analysis in section 5.2 reveals that the model economy calibrated to a time-share target in the range of 90 to 85 percent can account for the cross-country evidence

\footnotetext{
${ }^{13}$ Klenow and Rodriguez-Clare (1997) argue that primary enrollment rates vary much less across countries than secondary enrollment rates. Thus, by using secondary enrollment as a measure of human capital investment, MRW overstate the variance of human capital across countries.

${ }^{14}$ Manuelli and Seshadri (2005) report a TFP elasticity of output per worker of 9 when both TFP and demographic factors are allowed to vary across countries. We estimate the elasticity to be 6.6 when demographic factors are kept constant to U.S. levels using the results in Table 4, page 24.
} 
on schooling and income, the cross-country evidence on Mincer returns to schooling, and is consistent with evidence on immigrant's earnings from Borjas (1987). It follows that an amplification effect of relative TFP differences in the range from 2.77 to 3.6 is plausible and that the cross-country variation in output per worker can be explained with relative TFP differences in the range from 2.3 to 3 . In a closely related study that follows a different methodology from ours, Hendricks (2002) also concludes that TFP differences of a factor of 3 are needed to account for the cross-country data. Hendricks performs a growth accounting exercise without assuming a specific functional form for human capital accumulation by directly measuring cross-country differences in school quality using data on relative earnings (adjusted by schooling levels) of immigrants in the United States. To generate comparable statistics from our model, we simulate immigrants from four potential source countries differing with respect to their TFP. For each source country, we select immigrants with an average level of schooling consistent with the data reported in Hendricks. We assume that, conditional on the level of schooling, immigrants are randomly drawn from the distribution of ability types in the source country. We find that an immigrant from a country with an income in the range of 10 to 20 percent of U.S. income, has relative earnings of about 84 percent of a similarly schooled U.S. worker, which is close to the value of 83 percent reported by Hendricks (see Figure 4).

We conclude that our benchmark economy is roughly consistent with Hendrick's data. Importantly, the economy with a time share of 85 percent implies relative earnings of immigrants that are too low compared to the data (see fourth panel in Figure 4). One interpretation of this result is that this economy generates differences in the quality of human capital that are too large compared to the data. An alternative interpretation is that the assumption that immigrants are randomly drawn from the talent distribution (conditional on schooling levels) is not correct. Instead, if immigrants are positively selected, the implications of the model economy with a time share of 85 percent could well be consistent with the data. Nevertheless, this economy would imply an amplification effect of 3.6, which is still substan- 
tially below the value of 6.6 found by MS. An amplification effect of 6.6 would obviously imply much larger quality differences in schooling across countries than the ones obtained in our baseline calibration. We thus side with Hendricks in concluding that accounting for the observed cross-country income differences on the basis of human and physical capital alone would require implausibly large degrees of self-selection in unobserved skills among immigrants. Moreover, our findings suggest that TFP is more important than is apparent in Hendrick's careful analysis since TFP differences can account for most of the cross-country variation in average years of schooling and in schooling quality.

\subsection{Productivity of investment goods}

Our quantitative analysis has focused on TFP as the main force driving output per worker differences across countries. One implication of this assumption in the context of a neoclassical growth model is that the physical capital to output ratio is roughly constant across economies. In the data, the capital to output ratio differs across countries and the literature has suggested productivity differences in the production of investment goods as one of the explanations (e.g. Restuccia and Urrutia (2001) and Hsieh and Klenow (forthcoming)). Hence, it is of interest to ask whether our results change if, in addition to TFP differences, we allow for productivity differences in the investment-goods sector. We simulate an economy that features a productivity of investment goods that is $1 / 4$ of the benchmark economy, i.e., $A_{k}=1 / 4$. This productivity difference is roughly consistent with the difference in the relative price of capital between rich and poor countries (see for instance Jones (1994) and Restuccia and Urrutia (2001)). In addition, we reduce the TFP level of this economy so that output per worker relative to the benchmark economy is the same as in the economy with relative TFP of $1 / 3$ (and no difference in the productivity of investment goods). A relative TFP of $3 / 5$ in this economy produces an output per worker that is $1 / 21$ of the benchmark economy. Table 9 reports statistics for this economy and the economy with relative TFP of $1 / 3$ in the baseline specification. We observe that the aggregate statistics are quite similar 
except for the capital-to-output ratio, which in the economy with low productivity of investment goods is $1 / 5$ of the value in the benchmark economy. We conclude that the implications of our model are robust to the source of productivity differences. Low investment in human capital in poor economies is driven by low wage rates, regardless of whether low wage rates are the result of low TFP, low physical capital to output ratio, or a combination of both.

Table 9: Sectoral TFP Differences in the Model

\begin{tabular}{lccc}
\hline Relative TFP $(A)$ & 1 & $1 / 3$ & $3 / 5$ \\
Rel. Sector TFP $\left(A_{k}\right)$ & 1 & 1 & $1 / 4$ \\
Rel. $Y$ & 1 & $1 / 21$ & $1 / 21$ \\
Rel. $H$ & 1 & $1 / 4$ & $1 / 4$ \\
$K / Y$ & 2.8 & 2.7 & 0.6 \\
Rel. $K / Y$ & 1 & 1 & $1 / 5$ \\
Average Years of Schooling & 12.9 & 4.3 & 4.0 \\
Returns to Schooling $(\%)$ & 10.0 & 22.6 & 24.3 \\
\hline
\end{tabular}

\section{Conclusions}

We developed a quantitative theory of human capital with heterogeneous agents in order to assess the magnitude of cross-country differences in TFP that are needed to explain the variation in cross-country output per worker. A model with heterogeneous agents allows us to discipline the parameters governing human capital accumulation that are crucial for the quantitative implications of the theory. Our quantitative model produces a TFP elasticity of output per worker of 2.8. This implies that a 20-fold difference in output per worker can be explained by a 3-fold difference in TFP. The theory suggests that using Mincer returns to measure human capital understates human capital differences across countries by a factor of 2. Our quantitative theory does not only imply large differences in human capital across countries, but it also delivers differences in human capital quality that are consistent with (i) the evidence from earnings of immigrants in the United States, $(i i)$ the cross-country evidence on estimates of Mincer returns, and (iii) the evidence on the relationship between 
average years of schooling and per-capita income across countries. In our theory, countries with low TFP also exhibit (relative to the benchmark economy) high inequality in earnings and low intergenerational correlation of earnings. We leave for future work the quantitative evaluation of how cross-country differences in TFP, fiscal policies, and the support for public education affect economic inequality within countries. ${ }^{15}$

\footnotetext{
${ }^{15}$ There is abundant evidence in support of education and fiscal policies differences in developed and developing countries. For instance, not only poor countries tend to devote less public resources to education, but also they tend to support tertiary education disproportionally more than primary and secondary education relative to rich countries, with substantial distributional consequences.
} 


\section{References}

Aiyagari, R. S. (1994): "Uninsured Idiosyncratic Risk and Aggregate Saving," Quarterly Journal of Economics, 109, 659-84.

Barro, R., And J.-W. LEe (1996): "International Measures of Schooling Years and Schooling Quality," American Economic Review, 86(2), 218-23.

Bils, M., And P. Klenow (2000): "Does Schooling Cause Growth?," American Economic Review, 90(5), 1160-83.

BorJas, G. (1987): "Self-Selection and the Earnings of Immigrants," American Economic Review, 77(4), 531-53.

Davies, J., And J. Whalley (1989): "Taxes and Capital Formation: How Important is Human Capital?," Working Paper 2899, NBER.

Economic Report of the President (2004):. United States Government Printing Office, Washinghton.

Erosa, A., And T. Koreshkova (forthcoming): "Progressive Taxation in a Dynastic Model of Human Capital," Journal of Monetary Economics.

Fuster, L. (2000): "Capital Accumulation in an Economy with Dynasties and Uncertain Lifetimes," Review of Economic Dynamics, 3(4).

Haveman, R., and B. Wolfe (1995): "The Determinants of Children's Attainments: A Review of Methods and Findings," Journal of Economic Literature, 33, 1829-78.

Hendricks, L. (2002): "How Important is Human Capital for Development? Evidence from Immigrant's Earnings," American Economic Review, 92(1), 198-219.

Heston, A., R. Summers, and B. Aten (2002): Penn World Table Version 6.1. Center for International Comparisons at the University of Pennsylvania (CICUP).

Hsieh, C., And P. Klenow (forthcoming): "Relative Prices and Relative Prosperity," American Economic Review.

Jones, C. (1994): "Economic Growth and the Relative Price of Capital," Journal of Monetary Economics, 34, 359-82.

Keane, M. P., and K. I. Wolpin (2001): "The Effects of Parental Transfers and Borrowing Constraints on Educational Attainment," International Economic Review, 42(4), 1051-1103.

Kendrick, J. W. (1976): The Formation and Stocks of Total Capital. Columbia University Press (for the National Bureau of Economic Research), New York. 
Klenow, P., And A. Rodriguez-Clare (1997): "The Neoclassical Revival in Growth Economics: Has It Gone Too Far?," in NBER Macroeconomics Annual, ed. by B. S. Bernanke, and J. J. Rotemberg. MIT Press, Cambridge, MA.

Mankiw, N. G., D. Romer, and D. N. Weil (1992): "A Contribution to the Empirics of Economic Growth," Quarterly Journal of Economics, 107(2), 402-37.

Manueldi, R., And A. Seshadri (2005): "Human Capital and the Wealth of Nations," mimeo.

Mulligan, C. B. (1997): Parental Priorities and Economic Inequality. University of Chicago Press, Chicago.

(1999): "Galton versus the Human Capital Approach to Inheritance," Journal of Political Economy, 107(6), S184-S224.

National Center for Health Statistics (2004): Health, United States, 2004 With Chartbook on Trends in the Health of Americans. Hyattsville, Maryland.

Neal, D. A., And W. R. Johnson (1996): "The Role of Premarket Factors in Black-White Wage Differences," Journal of Political Economy, 104(5), 869-895.

Poterba, J. (1997): "The Estate Tax and After-Tax Investment Returns," Working Paper 6337, NBER.

Psacharopoulos, G. (1994): "Returns to Investment in Education: A Global Update," World Development, 22, 1325-43.

Restuccia, D., and C. Urrutia (2001): "Relative Prices and Investment Rates," Journal of Monetary Economics, 47(1), 93-121.

(2004): "Intergenerational Persistence of Earnings: The Role of Early and College Education," American Economic Review, 94(5), 1354-78.

Solon, G. (1999): "Intergenerational Mobility in the Labor Market," in Handbook of Labor Economics, Vol. 3A, ed. by O. C. Ashenfelter, and D. Card, pp. 1761-1800. North-Holland, Amsterdam.

Statistical Abstract of the United States (1999):. U.S. Government Printing Office, Washington, DC.

Stokey, N. L. (1998): "Shirtsleeves to Shirtsleeves: The Economics of Social Mobility," in Frontiers of Research in Economic Theory: The Nancy L. Schwartz Memorial Lectures, 1983-199\%., ed. by D. P. Jacobs, E. Kalai, and M. I. Kamien, pp. 210-41. Cambridge University Press, New York, NY.

Tauchen, G. (1986): "Finite State Markov Chain Approximations to Univariate and Vector Autoregressions," Economics Letters, 20(2), 177-81. 
Trostel, P. (1993): "The Effect of Taxation on Human Capital," Journal of Political Economy, 101(2), 327-50.

U.S. Census Bureau (2004): Table P-32 Educational Attainment-Full-Time, Year-Round Workers 18 Years Old and Over by Mean Earnings, Age, and Sex: 1991 to 2003. $<$ http://www.census.gov/hhes/www/income/histinc/p32.html >.

U.S. Department of Education (1996): Digest of Education Statistics. U.S. Government Printing Office, Washington, D.C.

U.S. Department of Education (2004): Digest of Education Statistics. U.S. Government Printing Office, Washington, D.C. 
Figure 1: Human Capital and Output

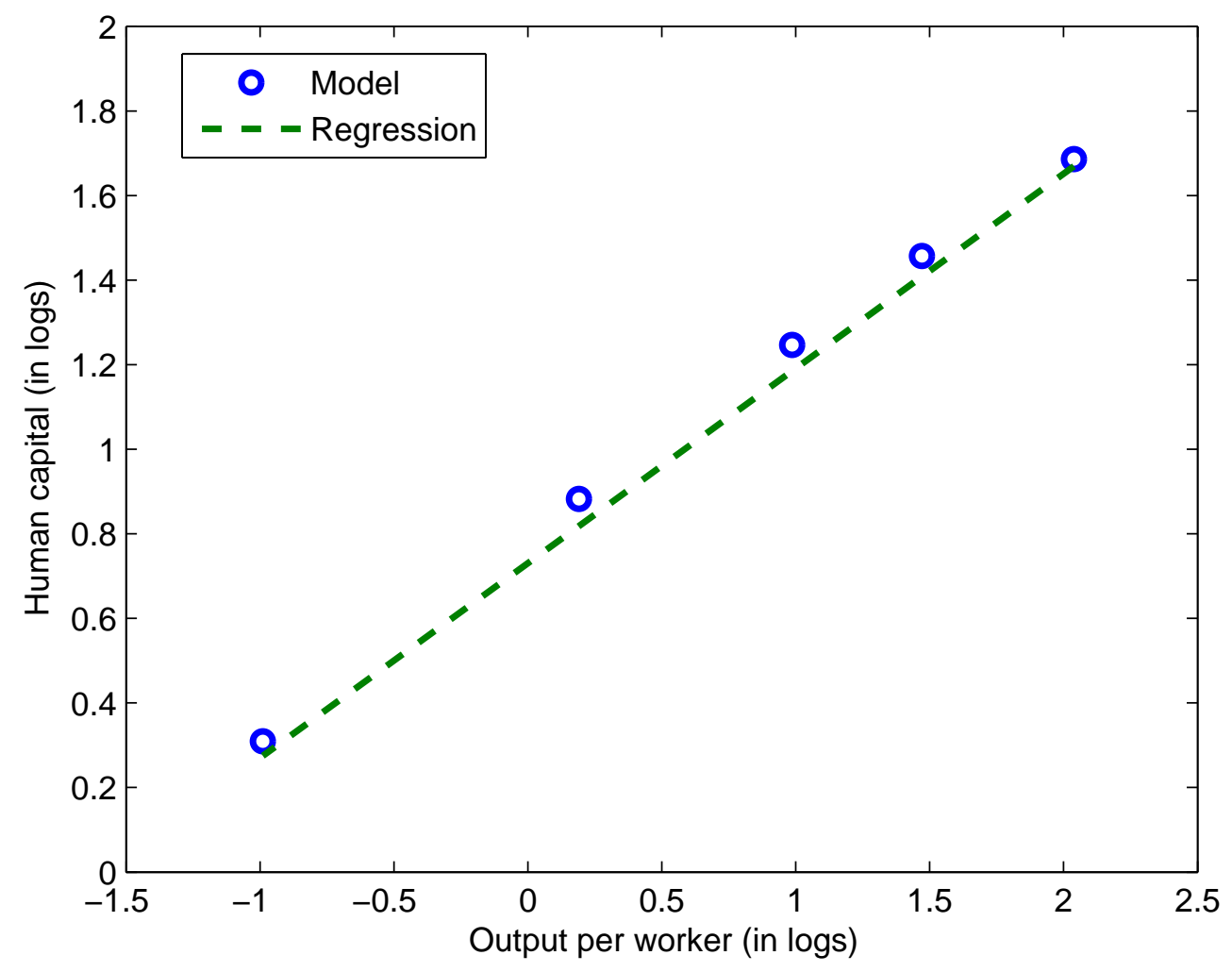

Model refers to economies with relative TFP of $1,0.8,2 / 3,1 / 2$, and $1 / 3$ in our baseline calibration. Regression refers to an OLS regression of log human capital on $\log$ output with a constant term resulting in: $\log (H)=0.7307+0.4605 \log (Y)$. 
Figure 2: Schooling and Output - Data vs. Model

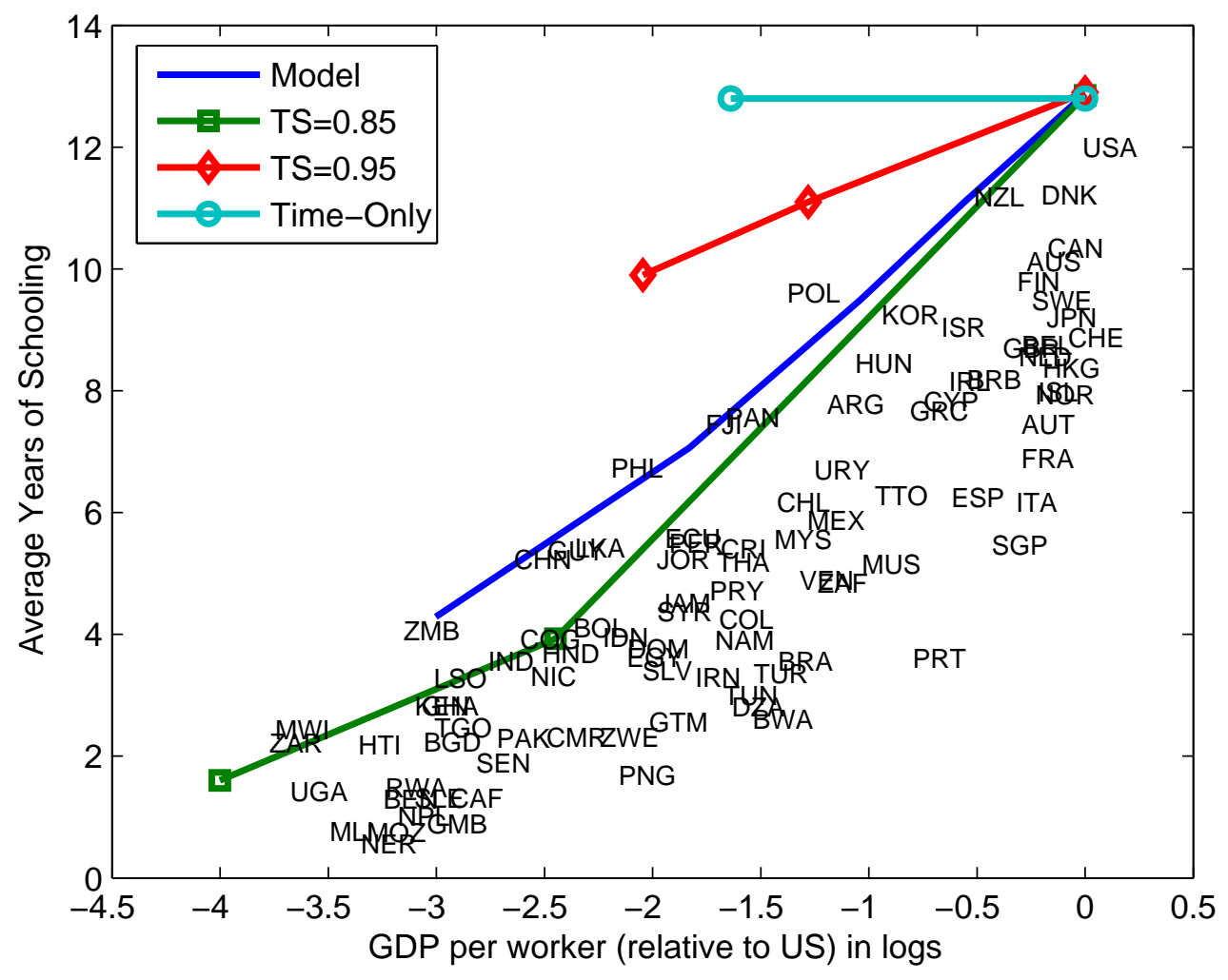

Data are from Barro and Lee (1996) and Heston, Summers, and Aten (2002). We take averages (five-year intervals) of GDP per worker in the data. This figure focuses on the averaged data for 1990. Model refers to economies with relative TFP of 1, 0.8, $2 / 3,1 / 2$, and $1 / 3$ in our baseline calibration. TS $=z$ refers to economies with relative TFP of $1,1 / 2$, and $1 / 3$ for a re-calibration of the model to a time share target of $z$ percent. Time-only model refers to economies with relative TFP of 1 and $1 / 3$ when human capital accumulation features only time inputs, i.e., $\eta=1$. 
Figure 3: Mincer Returns to Schooling - Data vs. Model

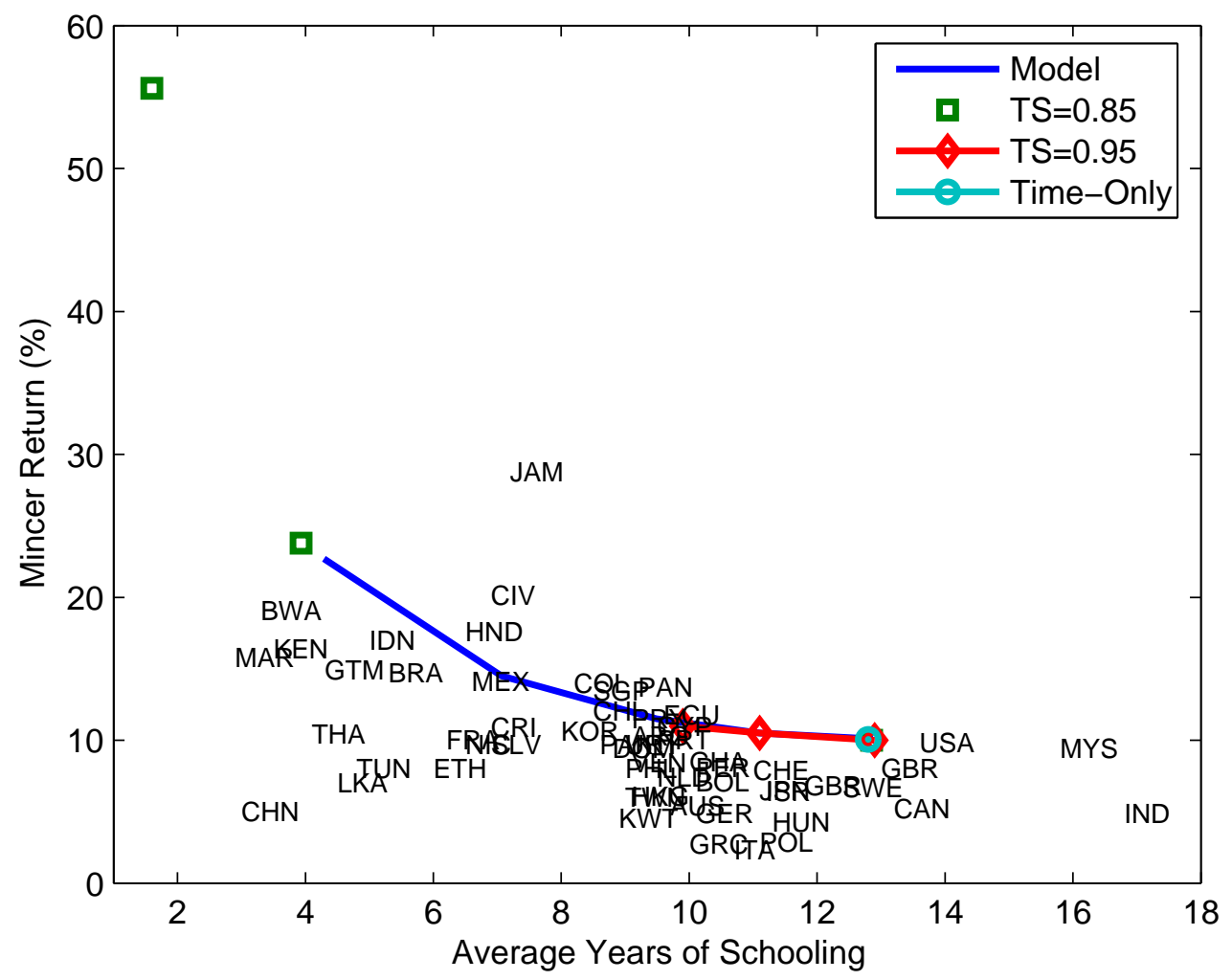

Model refers to economies with relative TFP of $1,0.8,2 / 3,1 / 2$, and $1 / 3$ in our baseline calibration (with a share of time inputs in the cost of education of 90 percent). TS $=z$ refers to economies with relative TFP of $1,1 / 2$, and $1 / 3$ for a re-calibration of the model to a time share target of $z$ percent. Time-only model refers to economies with relative TFP of 1 and $1 / 3$ when human capital accumulation features only time inputs, i.e., $\eta=1$. 
Figure 4: Relative Earnings of Immigrants
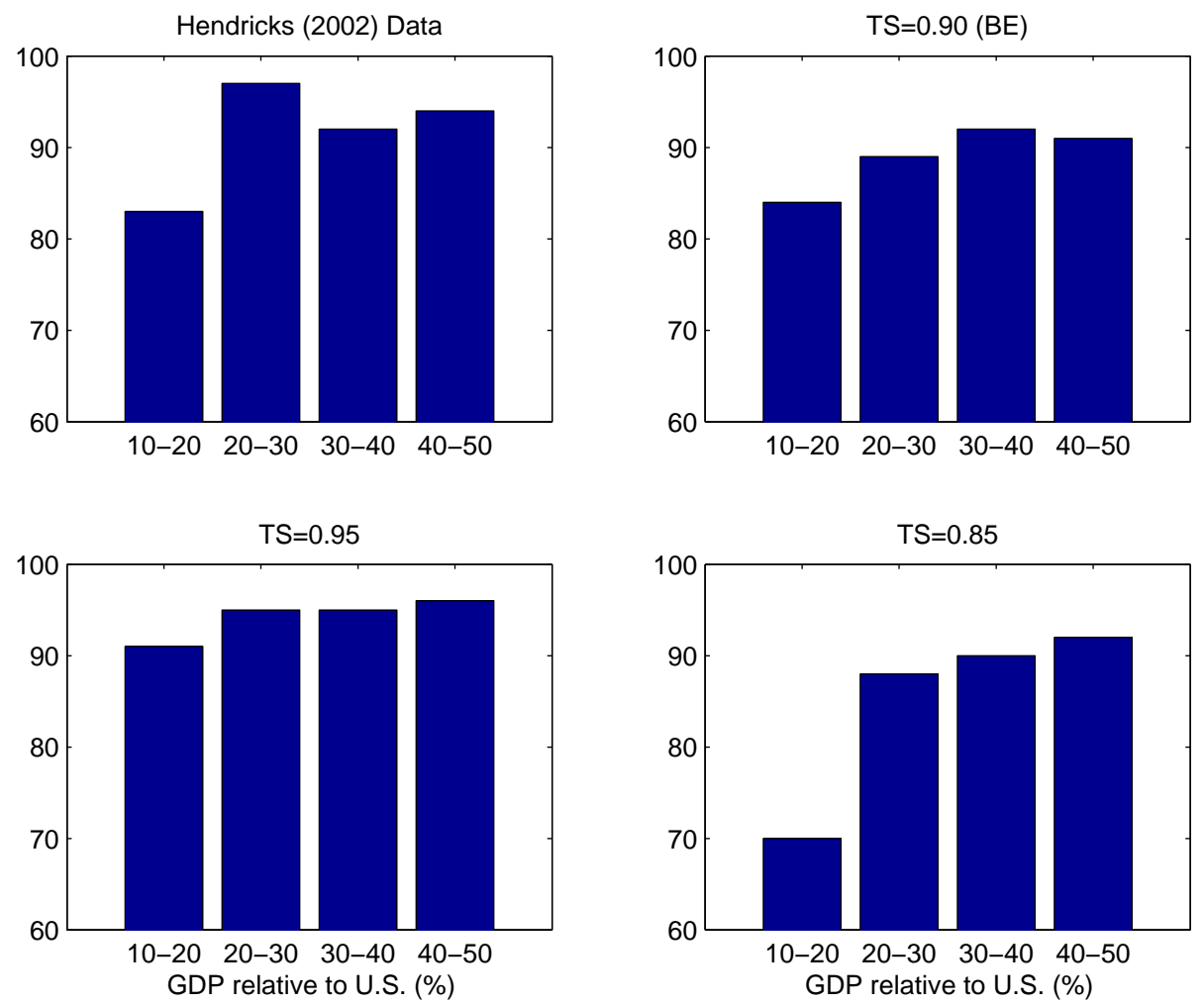

Data on relative earnings of immigrants across countries is from Hendricks (2002) and is adjusted by the level of schooling of the immigrant population. Comparable statistics are computed from the model for different values of the share of time in the total cost of education. According to Hendrick's data, the average years of schooling of the immigrant population to the United States from countries whose GDP per capita is between 10-20, 20-30, 30-40, and 40-50 percent of the United States is 12.8, 12.5, 12.8, and 11.7. We use this data to calculate relative earnings in the model for workers with the same average years of education. 